\title{
Pengaruh Pendapatan Daerah Sinergi dengan MP3EI Koridor Provinsi Kaltim
}

\author{
Abd.Rachim AF. \\ Universitas Widya Gama Mahakam Samarinda \\ abdrachim@uwgm.ac.id
}

\begin{abstract}
In total, Net Regional Income (PAD) gives share into Regional Income of East Kalimantan for $40.56 \%$, causing East Kalimantan Government to build Regional Company along with the total insertion (Investment) of IDR1,084.415 Billion. The execution of MP3EI by identifying 25 infrastructures, Road Constructions, Bridges, Airports, Harbors, Islands, and Electricity Power Plant plus the Railway and the Trains which support the motion of Main Economy Actions starting from the planning and the execution as well as Post - Actions.

MP3EI,the main corridor of East Kalimantan's Economic Development, will broaden and intensify the management of the Natural Resources. Economic Growth and Development Acceleration, through very comparative economic sources done in a region to be able for it to compete in making products with price - to - value that is able to compete locally, nationally, and globally.
\end{abstract}

Keyword : Regional income MP3EI East Kalimantan

\begin{abstract}
Secara totalitas Pendapatan Asli Daerah memberikan share terhadap Pendapatan Daerah Provinsi Kaltim 40,56 \% Memacu perekonomian daerah Pemerintah Provinsi Kaltim membentuk Perusahaan Daerah, dengan Penyertaaan Modal (Investasi) keseluruhan sebanyak Rp 1.084,415 milyar. Pelaksanaan MP3EI dengan mengidentifikasi 25 Infrastruktur meliputi Pembangunan Jalan, Jembatan, Bandara, Pelabuhan, Pulau, dan Pembangkit Tanaga Listrik serta Rel dan Kereta Api. yang mendukung pelaksanaan Kegiatan Ekonomi Utama mulai Perencanaan dan Pelaksanaan serta Pasca kegiatan.

MP3EI Koridor Pembangunan Ekonomi Utama Kaltim akan memperluas dan mengintensifkannya pengeloalaan sumber daya alam tersebut. Percepatan Pembangunan dan Pertumbuhan Ekonomi, melalui kajian sumber ekonomi yang sangat komparatif dilaksanakan di suatu daerah agar mudah bersaing dalam menghasilkan produk dan harga jual sehingga memungkin dapat bersaing ditinngkat lokal, nasional, regional dan global.
\end{abstract}

\section{Kata kunci : Pendapatan daerah sinergi MP3EI Kaltim.}

*). Guru besar ekonomi pembanguna dan keuangan negara \& daerah / Rektor Universitas Widya Gama Mahakam Samarinda. 


\section{A. PEDAhUluan}

1. Latar Belakang

Komponen Pendapatan Daerah diatur dalam Undang-undang nomor 33 tahun 2004 tentang Perimbangan Keuangan antara Pemerintah Pusat dan Pemerintah Daerah. dan Undang Undang nomor 28 tahun 2009 tentang Pajak Daerah dan Retribusi Daerah. Pemerintah Provinsi Kalimantan Timur, selain mendapatkan Pendapatan Asli Daerah (PAD) bersumber dari Pajak Daerah, Retribusi Daerah, Hasil pengelolaan Kekayaan Yang Dipisahkan dan lain-lain Pendapatan Daerah yang Sah., juga memperoleh Dana Perimbangan dari Pemerintah Pusat, baik bersumber dari bagi hasil pajak daerah maupun dari bagi hasil sumber daya alam meliputi, Pertambangan Umum,Perhutanan, Perikanan, Minyak Bumi dan Gas Alam serta berasal dari Dana Alokasi Umum (DAU) dan Dana Alokasi Khusus (DAK). Besarnya perimbangan yang diperoleh Provinsi Kalimantan Timur, karena daerah ini memiliki sumber daya alam (SDA) yang sangat besar sumbangannya dalam perekenomian daerah dan nasional, namun perlu diingat bahwa sebagaian besar Sumber Daya Alam (SDA) tersebut merupakan sumber daya alam yang tidak dapat di perbaharui seperti minyak bumi, gas alam dan batu bara, yang suatu saat berkurang.

Bertitik tolak pemikiran tersebut di atas, maka peranan Pendapatan Asli Daerah di masa mendatang menjadi sangat penting karena dana perimbangan dari sumber daya alam yang tidak dapat diperbaharui tersebut akan semakin berkurang. Untuk itu perlu digali sumber pendapatan lain yang tidak tergantung kepada sumber daya alam. Demi mengatasi kelangsungan Pendapatan Daerah Provinsi Kalimantan Timur.

2. Tujuan dan Manfaat Penelitian

Tujuan Penelitian untuk mengetahui Pengaruh pendapatan daerah Sinergi dengan MP3EI Koridor Provinsi Kaltim. Sedangkan manfaat penelitian bagi Pemerintah daerah dapat digunakan sebagai bahan kebijakan untuk meningkatkan kinerja Pemerintah daerah sesuai dengan MP3EI Koridor Kaltim.

\section{B. KAJIAN TEORITIS}

Peningkatan Pendapatan Daerah melancarkan penyelenggaraan roda Pemerintahan Daerah, daerah diberikan urusan untuk memungut pajak daerah dan 
retribusi daerah serta berkreasi untuk membangun badan usaha .Secara anatomi, Anggaran Pendapatan dan Belanja Daerah (APBD), adalah rencana keuangan tahunan pemerintah daerah yang dibahas dan disetujui bersama oleh Pemerintah Daerah dan DPRD, ditetapkan dengan peraturan daerah, meliputi Pendapatan daerah, Belanja daerah dan Pembiayaan daerah. Untuk memperbesar pendapatan daerah, diperlukan peningkatan kapasitas pembangunan daerah melalui kegiatan Sosial Ekonomi Daerah, dari hasil tersebut memberikan dampak terhadap pertumbuhan ekonomi dan peningkatan kesejahteraan masyarakat pada gilirannya meningkatkan Pendapatan Daerah.

Kenyataanya Ketergantungan Pemerintah Daerah sangat besar kepada Pemerintah Pusat, sehingga pelaksanaan pembangunan Daerah sangat ditentukan oleh Pemerintah Pusat dalam mentransfer dana perimbangan, kondisi ini menuntut kreatif dan inovatif dalam penyelenggaraan Pendapatan Daerah. Ketergantungan yang besar pemerintah daerah dari Pemerintah Pusat, memerlukan perbaikan Sistem dan Prosedur pemungutan juga diperlukan kreatifitas dan Inovasi dalam pengembangan sumber pendapatan daerah.

Pendapatan Daerah yang dikelola harus disesuaikan dengan urusan yang telah ditetapkan dalam Peraturan perundang-undangan. Berdasarkan Undang-undang nomor ; 33 tahun 2004 tentang Perimbangan Keuangan antara Pemerintah dengan Pemerintah Daerah . pada pasal 5 disebutkan. Penerimaan Daerah dalam pelaksanaan desentralisasi terdiri atas pendapatan daerah dan pembiayaan. Pendapatan daerah terdiri dari Pendapatan Asli Daerah, Dana Perimbangan dan lain-lain pendapatan. Pembiayaan bersumber dari Sisa lebih perhitungan anggaran daerah, penerimaan pinjaman daerah,dana cadangan daerah dan hasil penjualan kekayaan daerah yang dipisahkan.

\section{METODE PENELITIAN.}

1. Lokasi Penelitian

Penelitian ini dilakukan pada Pemerintah Provinsi Kalimantan Timur dengan fokus penelitian pada penyusunan dan penggunana anggaran untuk belanja daerah tahun 2012 dikaikan dengan kebijakan MP3 EI koridor Kaltim.

2. Jenis Penelitian

Penelitian ini merupakan penelitian studi kasus yang menggunakan dan mengkaji data-data yang diperoleh dan menarik kesimpulan dari hasil kajian. Studi kasus ini bertujuan untuk memberikan gambaran efektifitas dan efisiesi 
penggunaan angaran belanaja daerah untuk roda pemerintahan, pembangunan dan kemasyarakatan.

3. Data dan Sumber Data

Data yang digunakan dalam penelitian ini merupakan data sekunder dan bersifat kuantitatif, berbentuk penjabaran APBD pemerintah Provinsi Kalimantan Timur tahun 2012

\section{HASIL PENELTIAN}

Pendapatan Daerah yang terdiri dari Pendapatan Asli Daerah, Dana perimbangan , Lain-lain Pendapatan Yang Sah dan Sisa Lebih Anggaran Tahun Lalu. Tahun Anggaran 2012 ditetapkan Target Pendapatan Daerah sebagai berikut :

\begin{tabular}{|c|c|c|c|}
\hline NO & PENDAPATAN DAERAH & $\begin{array}{l}\text { TARGET } \\
\text { (Dalam 000.000) }\end{array}$ & $\begin{array}{l}\% \\
\text { Total }\end{array}$ \\
\hline \multirow[t]{20}{*}{1.} & Pendapatan Asli Daerah & Rp. 4.303.713,- & 40,56 \\
\hline & a. Pajak Daerah & Rp. $3.558 .500,-$ & 33,54 \\
\hline & - Pajak Kendaraan Bermotor & Rp. $\quad 550.000,-$ & 5,18 \\
\hline & - $\quad$ Bea Balik Nama Kendaraan Bermotor & Rp. $\quad 900.000,-$ & 8,48 \\
\hline & - $\quad$ Pajak Bahan Bakar Kendaraan Bermotor & Rp . 2.100.000,- & 19,79 \\
\hline & - $\quad$ Pajak Pengambilan \& Pendapatan Air Permukaan & Rp. $\quad 8.500,-$ & 0,08 \\
\hline & b. Retribusi Daerah & $17.994,-$ & 0,17 \\
\hline & - Jasa Umum & $14.032,-$ & 0,13 \\
\hline & - Jasa Usulan & $3.925,-$ & 0,04 \\
\hline & - $\quad$ Perijinan Tertentu & $37,-$ & 0,00 \\
\hline & c. Hasil Pengelolaan Kekayaan yang dipisahkan & $222.692,-$ & 2,69 \\
\hline & - Laba Perusahaan Milik Daerah & $219.817,-$ & 2,1 \\
\hline & ○ Perusda Melati Bhakti Satya & $500,-$ & 0,00 \\
\hline & ○ Perusda Kehutanan & 97,- & 0,00 \\
\hline & o Perusda Perkebunan & $220,-$ & 0,01 \\
\hline & o Perusda Pertambangan & $15.000,-$ & 0,14 \\
\hline & o Perusda PT. Mandiri Pratama & $4.000,-$ & 0,02 \\
\hline & o Perusda Bank Pembangunan Daerah & $200.000,-$ & 1,18 \\
\hline & $\circ$ Perusda Kelistrikan & Rp. & - \\
\hline & - $\quad$ Investasi Kepada Pihak Ketiga & & \\
\hline
\end{tabular}




\begin{tabular}{|c|c|c|c|}
\hline & ○ Mall Lembuswana & $1.000,-$ & 0,01 \\
\hline & PT Askrida & $1.875,-$ & 0,02 \\
\hline & d. Lain-lain Pendapatan Daerah Yang Sah & $504,-$ & 0,00 \\
\hline \multirow[t]{15}{*}{2.} & Dana Perimbangan & Rp. 4.392.796,-- & 41,40 \\
\hline & a. Bagi Hasil Pajak & $\begin{array}{ll}\text { Rp. } & 600.000,-\end{array}$ & 5,65 \\
\hline & - Pajak Bumi dan Bangunan & $350,000,-$ & 3,29 \\
\hline & $-\quad$ BPHB & Rp. & - \\
\hline & - $\quad$ PPH Pasal 21 & $250.000,-$ & 2,35 \\
\hline & b. Bagi Hasil Bukan Pajak & Rp. $3.687 .267,-$ & 34,75 \\
\hline & - Provisi Sumber Daya Hutan & Rp. $\quad 30.000,-$ & 0,28 \\
\hline & - Ijin Usaha Pertambangan & $3.600,-$ & 0,03 \\
\hline & - Landrent & $4.500,-$ & 0,04 \\
\hline & - $\quad$ Iuran Eksplorasi/Royalti & $780.000,-$ & 7,35 \\
\hline & - $\quad$ Minyak Bumi & Rp. $\quad 779.490,-$ & 7,34 \\
\hline & - Gas Alam & Rp. 2.089.677,- & 19,69 \\
\hline & c. Dana Alokasi Umum (DAU) & Rp. $\quad 52.637,-$ & 0,49 \\
\hline & d. Dana Alokasi Khusus (DAK) & $34.616,-$ & 0,32 \\
\hline & e. Dana Insentif Daerah & $18.274,-$ & 0,17 \\
\hline 3. & Lain-lain Pendapatan yang Sah & 414.013,- & 3,90 \\
\hline \multirow[t]{2}{*}{4.} & Sisa Lebih Tahun lalu & Rp. $1.500 .000,-$ & 14,13 \\
\hline & TOTAL PENDAPATAN DAERAH & Rp. 10.610.522,- & 100 \\
\hline
\end{tabular}

\section{E. ANALISIS DAN PEMBAHASAN}

\section{Pendapatan daerah dan perusahaan daerah}

Penelitian ini menggunakan teknik pengumpulan data berupa dokumentasi dari APBD Provinsi KalimantanTimur tahun 2013. Secara totalitas Pendapatan Asli Daerah memberikan share terhadap Pendapatan Daerah Provinsi Kaltim 40,56 \% dapat dikatagorikan cukup, dengan masing-masing share Pajak Daerah 33,54 \%, Retribusi Daerah 0,17 \%, Pengelolalaan Kekayaan Yang Dipisahkan 2,10 \%, Secara Parsial jika dicermati, share tersebut sangat didominasi pendapatan dari sumber Pajak Kendaraan Bermotor, Bea Balik Nama Kendaraan Bermotor dan Pajak Bahan Bakar Kendaraan Bermotor, secara keseluruhan 33,45 \% . Memperhatikan kondisi diatas, seharus tidak boleh berbangga dengan jumlah Pendapatan Asli Daerah 
yang besar, karena bersumber dari Sumber Daya Alam tidak dapat diperbaharui (Unrenewable) selain itu pelaksanaan pemungutan untuk menghimpun dana tersebut relatif mudah atas obyek pajak yang dikenakan.Seharusnya untuk menjaga keberlanjutan pendapatan daerah yang diorientasikan bersumber yang terbaharukan.

Dalam menggerakan dan memacu perekonomian daerah Pemerintah Provinsi Kaltim membentuk Perusahaan Daerah, dengan Penyertaaan Modal (Investasi) data tahun 2011 Bankaltim Rp 728,915 milyar, Perusda Bara Kaltim Sejahtera Rp 5 milyar, Kehutanan Sulva Kaltim Sejahtera Rp 5 milyar, Perkebunan Kaltim Utama Rp 27 milyar, Listrik Kaltim Rp 126 milyar, Melati Bhakti Satya Rp 32,500 milyar dan Inters Join Operation Body Rp 160 milyar. Keseluruhan sebanyak Rp 1.084,415 milyar diatas Rp 1 Triliun dana diinvestasikan pada perusahaan.

Membangun perusahaan minimal yang harus ditetapkan adalah apakah perusahaan tersebut sebagai Publik Commersial, Publik Utilities atau Publik Service. Prinsip dasar ini harus dicantumkan dalam pembentukan yang dituangkan dalam Peraturan Daerah. Jika perusahaan didirikan dengan tujuan Publik Comersial, maka wajib laba, jika Publik Utilities, boleh saja kembali pokok dan public Service, tidak masalah rugi yang dibiayaai pendapatan daerah lainnya. Tetapi apa kenyataanya dana sebagai investasi kepada perusahaan daerah tahun 2012 target memberikan keuntungan sebagai share terhadap pendapatan daerah yakni Bankaltim Rp 200 milyar, , Perusda Bara Kaltim Sejahtera Rp 15 milyar, Kehutanan Sulva Kaltim Sejahtera Rp 0,097 milyar, Perkebunan Kaltim Utama Rp 0,22 milyar, Listrik Kaltim Rp ? milyar, Melati Bhakti Satya Rp 0,50 milyar dan Inters Join Operation Body Rp 2,87 milyar. Keseluruhan Keutungan Perusahaan Daerah target tahun 2012 sebesar Rp 222.,69 miliyar Data ini menunjukan mana perusahaan daerah yang harus ditinjau kembali keberadaanya dengan mempertimbangkan ketiga azas tersebut di atas dan keuntungan yang diberikan perusahaan daerah terhadap Pendapatan Daerah. Dengan munguji melalui Marginal Eficiensi Of Capital (MEC). Jangan sampai keberadan Perusahaan Daerah menjadi parasit atau duri dalam daging Pendapatan Daerah/APBD Provinsi Kaltim. 


\section{Pendapatan daerah Sinergi dengan MP3EI koridor Kaltim.}

Berkait dengan Target Pemerintah Pusat melaksanakan Masterplan Percepatan dan Perluasan Pembangunan Ekonomi Indonesia (MP3EI) dimana Kaltim masuk Koridor 3 Kalimantan dan secara khusus Kalimantan Timur dengan kegiatan Ekonomi Utama Minyak dan Gas, Batu Bara, Bauksit/Alumina, Perkayuaan dan Kelapa Sawit. Guna mewujudkan Masyarakat Indonesia yang Mandiri, Maju, Adil dan Makmur. Rencana tersebut dengan ditetapkannya Peraturan Presiden Republik Indonesia nomor 32 tahun 2011. Melalui MP3EI ini, tema baru pembangunan diarahkan pada peningkatan nilai tambah, pembangunan ekonomi yang beragam dan inklusif, menjaga keuntungan kompetitif, menekankan pembangunan transportasi yang seimbangan antara darat, laut dan udara dan pendanaan dilakukan kerjasama antara Pemerintah dan swasta.

Pelaksanaan MP3EI dengan mengidentifikasi 25 Infrastruktur meliputi Pembangunan Jalan, Jembatan, Bandara, Pelabuhan, Pulau, dan Pembangkit Tanaga Listrik serta Rel dan Kereta Api. yang mendukung pelaksanaan Kegiatan Ekonomi Utama mulai Perencanaan dan Pelaksanaan serta Pasca kegiatan, yang juga harus mempersiapkan implikasi dan dampaknya terhadap sosial ekonomi dan lingkungan yang negatif dan postif dalam mendukung pencapaian tujuan. Disinilah peran Pemerintah Provinsi Kaltim untuk menjabarkan rencana besar dari MP3EI khusus berkaitan dengan koridor pembangunan ekonomi utama Kaltim, sehingga sinergi pembangunan dan pendapatan dapat diketahui guna menetapkan kebijakan yang harus dilaksanakan.

\section{Ekonomi utama pembangunan Kaltim.}

Sumber daya alam Kaltim dari pengamatan kisaran sejak tahun 1960 Kaltim jual rotan dan damar, 1970 jual kayu, 1980 jual minyak, 1980 jual gas, 1990 jual emas, 2000 buka hutan bakau untuk tambak udang dan tahun 2010 jual batu bara. Apa yang terjadi kita tinggalkan bekasnya seperti di Loa Kulu, Sanga-Sanga, Anggana, Teluk Bayur, Loa Janan dan Kalian. Kedepan melalui MP3EI Koridor Pembangunan Ekonomi Utama Kaltim akan memperluas dan mengintensifkannya pengeloalaan sumber daya alam tersebut. Percepatan Pembangunan dan Pertumbuhan Ekonomi, melalui kajian sumber ekonomi yang sangat komparatif dilaksanakan di suatu daerah agar mudah bersaing dalam menghasilkan produk dan harga jual sehingga memungkin dapat 
bersaing ditinngkat lokal, nasional, regional dan global. Semua itu harus dilaksanakan untuk pembangunan dan pertumbuhan ekonomi disatu sisi dan lingkungan dan pemberdayaan dan kearifan lokal disisi lain juga harus mendapat perhatian.

Berkaca data Statistik Kemiskinan Kaltim tahun 2010 secara relatif terutama daerah sebagai lumbung Sumber Daya Alam cukup besar dan beranda Kaltim,Tingkat Kemiskinan cukup tinggi, yakni Kabupaten Malinau 15,13\%, Bulungan 14,58 \%, Tana Tidung 13,89\% Nunukan 12,45\%, Kutai Timur $11,39 \%$, Penajam Paser Utara 10,47 \% Kota Tarakan 10,23 \% Kabupaten Kutai Barat 9,90 \%, Kutai Karartanegara 8,69 \%, Kota Bontang 6,67 \%, Kabupaten Berau 6,60 \%, Kota Samarinda 5,21 \% dan Balikpapan 4,07 \%. Data menggambarkan daerah pedesaan lebih tinggi dibanding daerah perkotaan tingkat kemiskinan, hal ini menjadi anomaly pembangunan daerah dimana daerah produk tingkat kemiskinan tinggi. Ini tidak lain bagaimana anomali sumberdaya Kaltim dapat terhindar, dengan meninggalkan persoalan kehidupan kini dan masa mendatang, semua ini merupakan tanggung jawab bersama, yang seharusnya diarahkan oleh Pemerintah Provinsi dan Kota/Kabupaten se Kaltim. 


\section{A. KESIMPULAN DAN IMPLIKASI}

\section{Kesimpulan}

Berdasar hasil kajian dan pembahasan maka dapat diambil kesimpulan sebagai berikut :

a. Secara totalitas Pendapatan Asli Daerah memberikan share terhadap Pendapatan Daerah Provinsi Kaltim 40,56 \% dapat dikatagorikan cukup, dengan masing-masing share Pajak Daerah 33,54 \%, Retribusi Daerah 0,17 $\%$, Pengelolalaan Kekayaan Yang Dipisahkan 2,10 \%, Secara Parsial jika dicermati, share tersebut sangat didominasi pendapatan dari sumber Pajak Kendaraan Bermotor, Bea Balik Nama Kendaraan Bermotor dan Pajak Bahan Bakar Kendaraan Bermotor , secara keseluruhan 33,45 \%

b. Memacu perekonomian daerah Pemerintah Provinsi Kaltim membentuk Perusahaan Daerah, dengan Penyertaaan Modal (Investasi) data tahun 2011 Bankaltim Rp 728,915 milyar, Perusda Bara Kaltim Sejahtera Rp 5 milyar, Kehutanan Sulva Kaltim Sejahtera Rp 5 milyar, Perkebunan Kaltim Utama Rp 27 milyar, Listrik Kaltim Rp 126 milyar, Melati Bhakti Satya Rp 32,500 milyar dan Inters Join Operation Body Rp 160 milyar. Keseluruhan sebanyak Rp 1.084,415 milyar.

c. Pelaksanaan MP3EI dengan mengidentifikasi 25 Infrastruktur meliputi Pembangunan Jalan, Jembatan, Bandara, Pelabuhan, Pulau, dan Pembangkit Tanaga Listrik serta Rel dan Kereta Api. yang mendukung pelaksanaan Kegiatan Ekonomi Utama mulai Perencanaan dan Pelaksanaan serta Pasca kegiatan, yang juga harus mempersiapkan implikasi dan dampaknya terhadap sosial ekonomi dan lingkungan yang negatif dan postif dalam mendukung pencapaian tujuan. Sumber daya alam Kaltim dari pengamatan kisaran sejak tahun 1960 Kaltim jual rotan dan damar, 1970 jual kayu, 1980 jual minyak, 1980 jual gas, 1990 jual emas, 2000 buka hutan bakau untuk tambak udang dan tahun 2010 jual batu bara. Apa yang terjadi kita tinggalkan bekasnya seperti di Loa Kulu, Sanga-Sanga, Anggana, Teluk Bayur, Loa Janan dan Kalian. Kedepan melalui MP3EI Koridor Pembangunan Ekonomi Utama Kaltim akan memperluas dan mengintensifkannya pengeloalaan sumber daya alam tersebut. Percepatan Pembangunan dan Pertumbuhan Ekonomi, melalui kajian sumber ekonomi yang sangat komparatif dilaksanakan di suatu 
daerah agar mudah bersaing dalam menghasilkan produk dan harga jual sehingga memungkin dapat bersaing ditinngkat lokal, nasional, regional dan global. Semua itu harus dilaksanakan untuk pembangunan dan pertumbuhan ekonomi disatu sisi dan lingkungan dan pemberdayaan dan kearifan lokal disisi lain juga harus mendapat perhatian.

d. Kemiskinan Kaltim tahun 2010 secara relatif terutama daerah sebagai lumbung Sumber Daya Alam cukup besar dan beranda Kaltim,Tingkat Kemiskinan cukup tinggi, yakni Kabupaten Malinau 15,13\%, Bulungan 14,58 \%, Tana Tidung 13,89\% Nunukan 12,45\%, Kutai Timur 11,39\%, Penajam Paser Utara 10,47 \% Kota Tarakan 10,23 \% Kabupaten Kutai Barat 9,90 \%, Kutai Karartanegara 8,69 \%, Kota Bontang 6,67\%, Kabupaten Berau 6,60 \%, Kota Samarinda 5,21 \% dan Balikpapan 4,07 \%. Data menggambarkan daerah pedesaan lebih tinggi dibanding daerah perkotaan tingkat kemiskinan

\section{Implikasi}

a. Bagi pemerintah daerah

Kondisi ini harus dilakukan Sinergi Pendapatan daerah dengan MP3Ei, untuk mempercepat perekonomian tumbuh dan berkembang.

b. Bagi Peneliti selanjutnya

Peneliti selanjutnya yang akan melakukan hal yang sama diharapkan mampu melakukan penelitian yang lebih mendalam mengenai kinerja belanja daerah Provinsi Kalimantan Timur. 


\section{DAFTAR PUSTAKA}

Undang-undang nomor 17 tahun 2003 tentangKeuangan Negara

Undang - undang nomor 1 tahun 2004 tentang Perbendahaaraan

Undang-undang nomor 33 tahun 2004 tentang Perimbangan Keuangan antara

Pemerintah Pusat dan Daerah

Undang undang Nomor 28 tahunPermendagri nomor 13 tahun 2006 jo 59 tahun 2007 tentang Pedoman Pengelolan Keuangan Daerah.

Peraturan Pemerintah nomor 56 tahun 2005 tentang Sistem Informasi Keuangan Daerah

Penjabaran Anggaran Pendapatan dan Belanja Daerah Provinsi Kalimantan Timur tahun 2012. 